
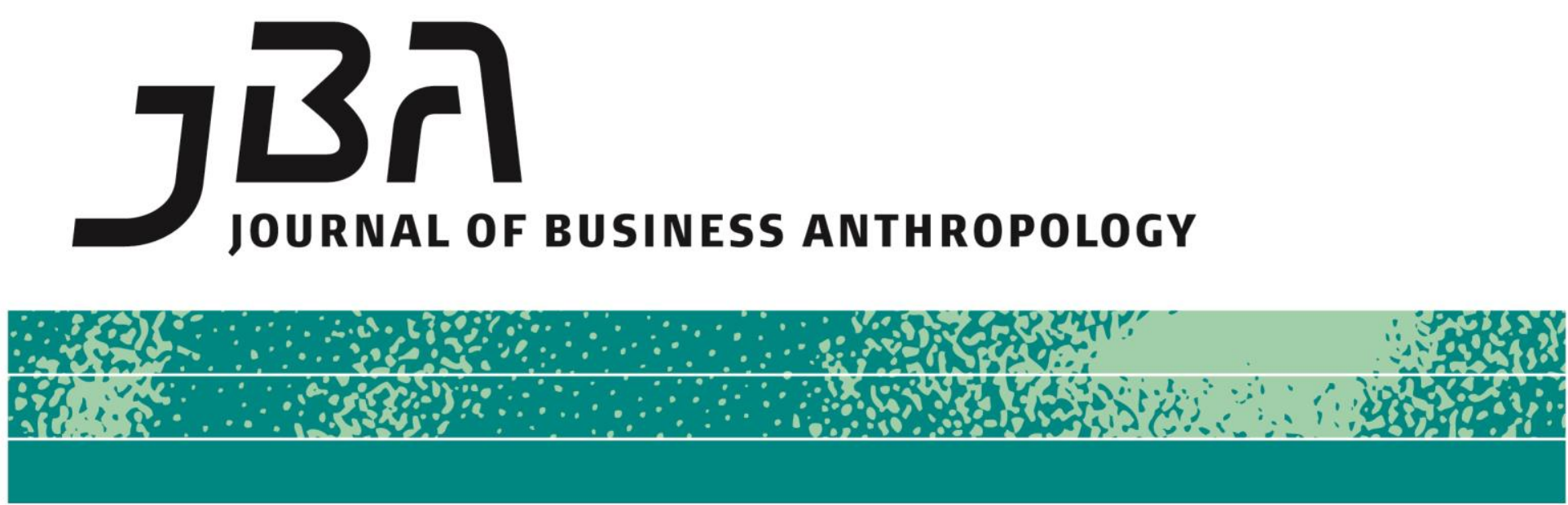

\title{
Notes on the State of Business Anthropology
}

\author{
Brigitte Jordan
}

Let me begin with an observation about ethnography in business settings. ${ }^{1}$ One of the interesting changes I have noticed is that there is now a new generation of managers who have been exposed to ethnography and its value in business. These are managers who no longer have to be persuaded that ethnography can do valuable, even strategic, work for them: both internally, as they deal with issues of work practice and company culture; and externally, as they look out at customer

Page 1 of 6

JBA 3(1): 126-131 Spring 2014

(C) The Author(s) 2014 ISSN 2245-4217

www.cbs.dk/jba relationships and supply lines in an increasingly digitized world.

This marks a stage quite different from the situation some years ago when we routinely had to convince managers that anthropological ethnography is no longer about tribes of natives in tropical jungles. Brinda Dalal and I wrote a paper about this with the title Persuasive Encounters, where we discussed the run of objections managers typically have. They would say things like:

- Very interesting, but not scientific;

- Takes too long and industry problems can't wait a year;

- You have a sample of one, and we have twelve teams.

With experience we were able to counter these kinds of objections with persuasive arguments from successful work that we had done. For

\footnotetext{
${ }^{1}$ I use the terms business, corporate and industrial anthropology or ethnography interchangeably here, given that there is no consensus on fine differentiation.
} 
example, the idea that research is scientific, when you identify a research hypothesis up front before beginning work, is effectively countered by pointing out that there are two ways of doing science: one is deductive and often used to validate existing hunches; the other is inductive and tends to lead to the discovery of previously unconsidered variables. The idea that ethnographic work is more time consuming than hypothesis testing can be rendered problematic by pointing out how much time hypothesis testing takes if done right.

And then there is the problem of sample size. Here it is useful to make clear that, in ethnography, we don't actually work with a sample of one since ethnography is fundamentally comparative. Contrary to popular belief, we are actually not interested in what a certain individual does or buys or thinks, but what people like her or him do or buy or think. We always investigate how widespread the findings from a first investigation are in a wider context. We then plan "ethnographic probes" that can tell us how local or systemic our findings might be. That allows ethnographers to modify research questions as they go, while deductive research is constrained by the requirements of the situation as they exist when dependent and independent variables and putative relationship are specified.

So I am suggesting that much of the heavy lifting work has been done. Ethnography in corporations and other large organizations has gained a kind of acceptance, even reputation, that it has not had before. Decades have passed by now during which large companies such as Microsoft, Intel and Xerox have had ethnographers on their staff. This is not to say that difficulties don't crop up here and there, but the out-ofhand, systematic kinds of dismissal that we used to face just simply don't exist anymore.

A conversation I recently had with the head of a hi-tech laboratory that Nissan has opened in Silicon Valley is typical. The Lab is charged with doing the research necessary to build autonomous vehicles (self-driving cars). For this manager in a global industry, there is absolutely no question that in addition to the automotive engineers and design specialists, he will need to hire ethnographers to make sure that these new vehicles get grounded socially-get a social life as we would say-and that they will fit into our rapidly changing society. He sees that driverless cars will generate widespread societal disruptions-ranging from new conceptualizations of risk, safety, and ownership to other, usually takenfor-granted, unexamined fundamental values. He posits widespread changes that might lead to fewer highways, and mobility for previously immobile populations such as the physically or cognitively impaired, the very young and the very old. He sees that driverless cars will generate disruptions and transformations that will likely surpass those that resulted from the introduction of cars in the first place. They will also generate new social relationships, an understanding of which is crucial 
for work on the driverless cars of the future. He actually said that "this is a socio-technical issue."

At the danger of being accused of self promotion, let me point to a book I recently edited. In Advancing Ethnography in Corporate Environments: Challenges and Emerging Opportunities, a group of experienced corporate ethnographers talk about their ongoing work in industry. Each topic in the book is covered by two seasoned experts who provide complementary views on contentious, often long-standing, issues and challenges in industrial anthropology. They write about such topics as:

- The benefits of conventional ethnographic methods versus technology-based methods;

- Anthropologists' and their customers' desire for theory, and the conflicting demands of practicality;

- Advantages of rapid ethnographic work, as compared to the limits of speed;

- Ethnographers as full-time employees in a company, or ethnographers working as outside consultants; and more.

One topic addressed in many chapters throughout the book is what many consider the most urgent issue confronting ethnography (and implicitly society) today: the digital revolution. We have had digitization (transformation of texts and other logocentric representations into digital form) for years now. What is truly new are the increasing capabilities and prevalence of sensors that, once installed, collect data automatically, relentlessly, "forever", without human input. Collecting data via sensing and behavioral tracking technologies generates what we might call "passive data", very much in contrast to the active data ethnographers collect in fieldnotes, still or video shots, by asking in situ questions, or other standard ethnographic methods.

Brian Arthur, a distinguished economist and complexity theorist, points out that almost all movement of goods and services now occurs over a global network of servers and sensors that operates without human involvement. These digital networks track information flows and make decisions that affect sales and inventory, financial transactions, tours, trades, and inquiries on an international market. Sociodigitization acts not only on physical bodies, artifacts, and properties-like the money in your pocket or the house you are trying to sell-but also on commercial real estate operations, designs of physical and virtual entities, air traffic and shipping control, and just about every other global operation that can be digitized. Thus major parts of workscapes and lifescapes exist now in the cloud, in digital codes, images, and text. They operate autonomously, meaning that human beings are no longer directly involved in running them. The data agglomerations they work with grow slowly, invisibly, inexorably, click by click and day by day, with no end in sight. They archive automatically, sense and execute remotely, run in parallel, 
reconfigure themselves on the fly, and increasingly have properties of self-organization and self-healing (Arthur 2011).

The digital transformation has an effect that is as yet little appreciated by researchers or clients, and is often simply dismissed. There certainly are many parts of people's lives that can still be treated in a manner that approximates life before the digital revolution. Conventional theories and methodologies would still be valid there. But the effects of sociodigitization are becoming more and more noticeable. Formerly fixed objects are becoming mobile. Thus the tropical mansion that was impossible to sell, becomes instantly actionable-that is to say, available for offers-just as are virtual immaterial properties, such as the music you are composing or the business proposal you are writing, even the book you are reading. In digital form they become newly mobile. They acquire a kind of hyper-mobility which makes them instantly available and globally actionable. In our geophysical world, where things and people have properties of location and physical substance, digitization is beginning to extend to all aspects of social, cultural and economic life.

I have argued for some time (most recently in Jordan 2013) that the massive digitally-based reorganization of the human lifescape may indicate that we are at another inflection point where the patterns of human evolution readjust to new technologies that have come into the system. I would suggest that some of this is evident in the tensions that have appeared in ethnographic methodology since the end of the last century, such as the rise of a primarily multi-sited ethnography that follows events and phenomena rather than being location bound; a shift in emphasis from "validating research" (tied to testing predetermined hypotheses) to "discovery research" (capitalizing on the emergence of new variables and approaches in the course of research) (Whalen and Whalen 2004); and in a general shift to complexity and multiple path analysis (Agar 2014, Arthur 2013).

We are now dealing with a new kind of open system, a system that cannot be pruned down through hypothesis testing, but that makes sense when described as a research space within which many different kinds of paths are possible. We can lay out a solution space that has competitive and strategic value by identifying some of those paths as more or less likely, recognizing that each change in the system provokes others that in turn influence the shape of the first through time. These are the developments that will define the state of business anthropology in the years to come.

For example, in the highly competitive autonomous vehicles field, there emerge two major paths developers could take on the design of driverless cars: each car company pursues its own design, or companies unite and work jointly toward some unified vision of what the driverless car would look like. At this point, it is unclear which way the driverless car will go. Will it be a generic high-tech vehicle, a kind of public service? 
Or will each car company brand its own, competing maybe on such things as interior design, functionalities desired by consumers, and the like? There is as yet not enough data to favor one side (or one of many possible others). There are simply too many interacting variables involved at this time.

In this new environment we will want to use conventional interviewing and observation techniques more selectively. For example, a question that frequently gets asked, when discussing some of the new technology-based research approaches such as Agent Based Modeling (ABM) or Big Data Analytics (BDA), concerns the role of ethnography in such work. Most of the time, an "ethnographic component" is added at or towards the end of such projects to provide some validation for the results. Instead of uniform advocacy of standard techniques, we may want to position "deep" ethnography-intensive face-to-face, on-site questionasking and observational shadowing, placed competitively and strategically at the very beginning of such projects, where they can support the discovery of otherwise unknowable hypotheses and approaches.

What is different? What is the new thing we have to offer? A world no longer filled with variables but with interacting, mutually generative processes, powered by sociodigitization. This is the world within which corporate anthropology and its partners exist now. It is the world within which anthropology has to find its vision, a vision that revolves around our clients' needs to deal with precisely that very same world.

\section{References}

Agar, Michael. 2013. The Lively Science: Remodeling Human Social Research. Minneapolis, MN: Mill City Press.

Arthur, Brian W. 2013. 'Complexity Economics: A Different Framework for Economic Thought.' Working Paper, Santa Fe Institute. To appear in his book Complexity Economics, Oxford University Press.

Arthur, Brian W. 2011. 'The Second Economy.' McKinsey Quarterly, October. (Available at

http://www.mckinseyquarterly.com/The second economy 2853)

Jordan, Brigitte. 2013. 'Pattern Recognition in Human Evolution and Why It Matters for Ethnography, Anthropology and Society.' Advancing

Ethnography in Corporate Environments: Challenges and Emerging Opportunities, edited by Brigitte Jordan, pp. 193-213. Walnut Creek, CA, Left Coast Press.

Jordan, Brigitte and Brinda Dalal. 2006. 'Persuasive Encounters: Ethnography in the Corporation.' Field Methods 18 (4):359-381. (Also Available at http://lifescapes.org/Papers/Persuasive\%20Encounters.pdf) 
Latham, Robert and Saskia Sassen. 2005. 'Digital Formations:

Constructing an Object of Study.' Digital Formations: IT and New

Architectures in the Global Realm, edited by Latham and Sassen, pp. 1-33.

Princeton: Princeton University Press.

Whalen, Marilyn, and Jack Whalen. 2004. 'Studying Workscapes.'

Discourse and Technology: Multimodal Discourse Analysis, edited by Philip

LeVine and Ron Scollon, pp. 208-229. Washington, D. C.: Georgetown

University Press.

Brigitte Jordan is a free-lance consultant anthropologist, currently working on a project that involves engineers in a Silicon Valley research lab, anthropological design competence, and the development of the driverless car of the future. Formerly, she was Principal Scientist at the Xerox Palo Alto Research Center (PARC) and Senior Research Scientist at the Institute for Research on Learning (IRL), where she was instrumental in the transformation of academic research techniques to methodologies appropriate for business and industry. As team member and project leader, she played a major role in developing basic concepts and methodologies that have become fundamental to research in business settings. These include Communities of Practice (COP), Authoritative Knowledge (AK) and Video-based Interaction Analysis. She carried out a number of high-profile projects in the corporate realm for which she received the Award for Excellence in Science and Technology of the Xerox Corporation. She may be reached at gitti.jordan@gmail.com. Her website with many of her publications is at www.lifescapes.org. 